\title{
THE VALUE OF BIM FOR PROJECT MANAGEMENT IN A SMART BUILT ASSET IN CHINA
}

\author{
Fang Fang ${ }^{1}$, Llewellyn C.M. Tang ${ }^{2}$, and Ren Bin ${ }^{3}$
}

${ }^{1}$ Chongbang Group, Shanghai, China

${ }^{2}$ Department of Real Estate and Construction, Faculty of Architecture, The Hong Kong University, Hong Kong, China

\author{
${ }^{3}$ China Eastern, Shanghai, China
}

\begin{abstract}
In China, real estate has been developed rapidly in the past 30 years. According to the market competition and demand, the owners and developers realize that the project management, which applies the information of consulting, design, implementation, and operations, should be more standardized. With the maturity of construction technology and the continuous updating of digital technology, e.g., Building Information Modeling (BIM), the trend to enter into a digital world is becoming widely accepted by the AEC sectors. The perspective of owners and developers in project management includes cost, schedule, quality, and safety. While the schedule of a project is one of the most critical factors, the high turnover demand of construction market, the design depth in many cases have not met the construction requirements during the construction of the stage of projects. In the construction stage, 4D simulation can be carried out, which is based on the construction organization and design, so that the reasonable construction progress can advise the project manager. This paper aims to explore the original scheme of 4D simulation and illustrates the other main application of BIM in Chinese construction market that how to deliver a smart built asset for users.
\end{abstract}

\section{Introduction}

This decade witnessed the benefits brought by the application of BIM. Many countries have been promoting BIM research and application very early, such as the US, Britain, Singapore, Japan and so on. While Ministry of Housing and Urban-Rural Development of the People's Republic of China (MOHURD) had issued the guidance of promoting the application of BIM. The guidance elaborates the objective of different participants of the projects, such as the owner, geological survey consultant, design consultant, general contractor and so on.

The client is the person or organization who pays money to another organization in return for a project. It is also used the terms "owners," "stakeholders" and "developers" in this paper. However, in many current projects, the proxy construction company acts as the consultant of the developer, playing the role of the project manager. It can also be considered as the client. The contractor is a construction company that is responsible for the construction and execution of the project according to the schedule, cost, quality and safety requirements of the owner through legal means.

\subsection{Project Management}

Project management is the management discipline that plans organizes and controls people, money, and cash so that projects are completed successfully despite all the risks.[1] The four key points of project management are cost, schedule, quality, and safety.

Cost refers to the total investment for the project, which is approved by the owner's board, including the land cost, construction cost, financial cost, management cost and so on. The project schedule is confirmed by the client's board, including the kick-off, completion, handover and so on. The technical requirements must be fulfilled the domestic specifications and mandatory regulations. Every country will establish a safety regulation and system in the field of construction. In this context, safety is based on the laws and regulations of China and matched the requirements of local safety supervise organization in the process of construction.

Figure 1 demonstrates the life cycle of a typical commercial project.

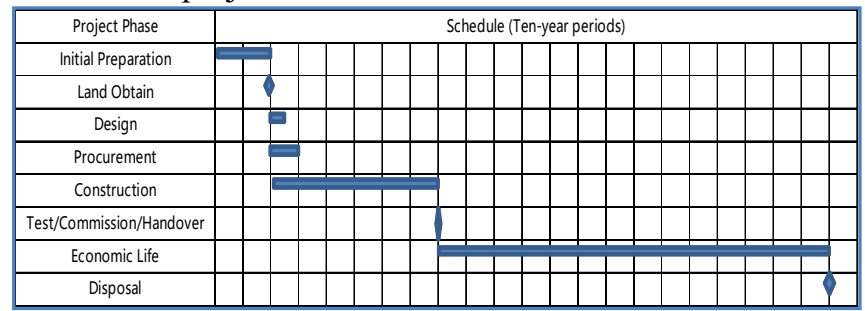

Figure 1 - Schedule

The life cycles of project management will be illustrated as the followings steps.

$>$ Due diligence, conceptual design.

$>$ A feasibility study, Estimation, and Financial study.

$>$ Confirm the specification and hand-over standard.

$>$ Construction drawings and procurement.

$>$ Construction.

$>$ Hand over the project.

$>$ Maintenance and operation

1.2 A Brief History of BIM

BIM was considered as the file that is created by the use of three-dimensional (3-D) computer-aided design (CAD) software programs. [2]In reality, the essential value of application of BIM is information. It reveals the data that can be used to analyze and predict outcomes throughout different phases of the building lifecycle. 
In 1975, "father of BIM" - Professor Chuck Eastman of Georgia science and Technology University created the BIM concept up to now. The research of BIM technology has gone through three stages: the germination stage, the generation stage, and the development stage.

1.2.1 In the UK, many design/construction companies have jointly established the "AEC (UK) BIM standard" project committee and set up "AEC (UK) BIM Standard" as a recommended industry standard. A series of BIM standards have been issued since 2007 as the following (included but not limited).

$>$ BS 1192:2007

Collaborative production of architectural, engineering, and construction information - Code of practice

$>$ PAS1192-2

Specification for information management for the capital/delivery phase of a construction project using building information modeling

$>$ PAS1192-3

Specification for information management for the operational phase of assets using building information modeling

$>$ PAS1192-4

Collaborative production of information, Fulfilling employer's information exchange requirements using COBie

$>$ PAS1192-5

Specification for security-minded building information modeling, digital built environments, and smart asset management

$>$ PAS1192-6

Specification for collaborative sharing and use of structured health and safety information using BIM

These standards define the relevant processes and requirements of BIM applications and make good explanations in information requirements, exchange, use, and other aspects in order to reduce construction waste and improve construction efficiency.

1.2.2 The application of BIM technology in China has been developing rapidly in 2016. Influenced by the overall demand of the reform and development of the developed countries and the construction industry, BIM technology is gradually popularised in the field of construction engineering. Most of the provincial governments have also introduced relevant BIM policies. Some provinces have already started the marketing and popularisation of BIM technology under the promotion of the government, association, and enterprises. The above contents are detailed in Figure 2.

1.2.3 The characteristics of BIM can be summarized as follows:

$>$ Visualization

$>$ Coordination

$>$ Simulation

$>$ Optimization

$>$ Parameterization

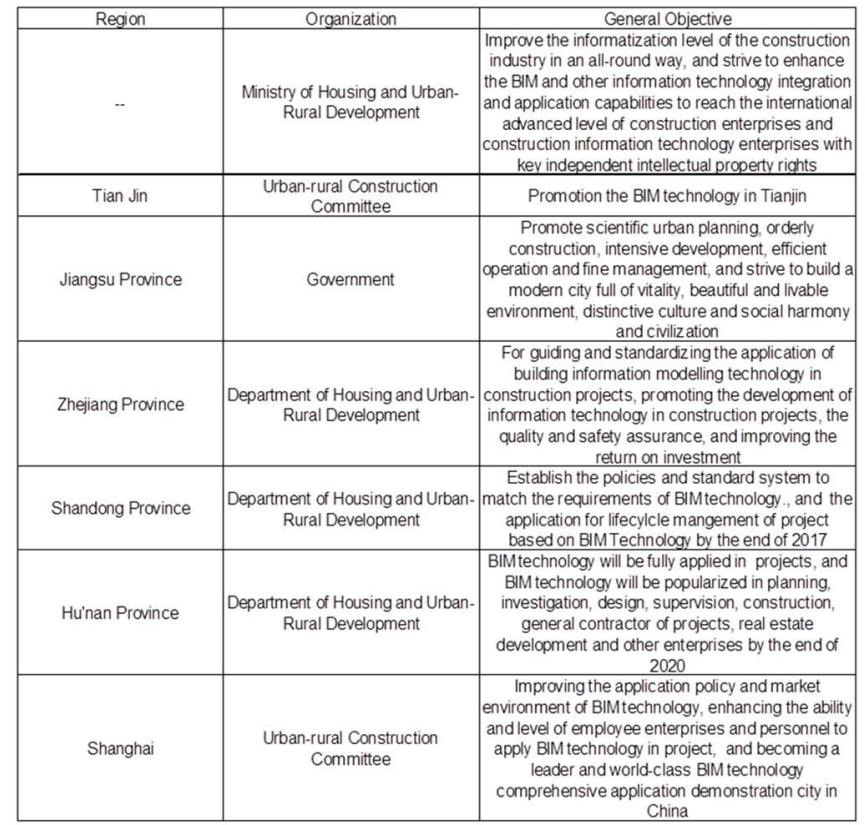

Figure 2 - Objective

\subsection{The Problem Statement}

Applications of BIM can be used for lots of aspects, such as concept design, cost estimation, and facility management and so on. The information that we can get out of BIM is based on what we input. According to the investigation, the current application of BIM project has some problems.

1.3.1 Employer's information requirements (EIR)

The employer's information requirements (EIR) shall obey the rules of "SMART", which is represented as specific, measurable, achievable, realistic and time-bound against. The investigation reveals that the primary purpose of EIR is included as the followings:-

$>$ Reduce the cost

$>$ Collision detection

$>$ Simulation

$>$ Comparison of design

$>$ Space management

$>$ Facilities management

1.3.2 Common data environment (CDE)

In the contemporary market, there is no mature regulation for BIM application in the AEC industry, which can define the common data environment and exchange information. When the modeling is completed, data is exchanged in the form of point-to-point, and the building information modeling is modified and applied separately. This will lead to the misunderstanding of the building information modeling, and cause to ambiguity in the communication and decision-making.

1.3.3 The type of information

The necessary information includes building component dimensions, space dimensions, material specifications, equipment parameters, and so on. More deep level information includes construction schedule, construction detail of architecture, installation, processing, and cost (including manual, material, and equipment).

The level of detail contained in the materials, objects, and systems is critical. These details compose the data used to 
analyze the model, so if this information is missing or incorrect, analysis cannot be useful to the employer.

\subsubsection{The problems}

$>$ As discussed in clause 1.3.1, EIR is the foundation for the application of BIM. Because developers are the ultimate beneficiaries, so the employer will be the primary user of BIM. However, the reality is, according to the Chinese AEC industry, the employer pays less attention in BIM application. EIR is usually not so clear that each participant cannot make a clarified common sense of delivery standards. The result is that the modeler does not understand the needs of users, and works with his experience.

$>$ On the other hand, employers are usually not professional designers and are not familiar with modeling requirements and specifications. Therefore, employers usually cannot provide suitable demand advice for EIR. So it is a gap between the modeler and the user.

$>$ Before adding the data to the elements and components, the modeler should issue an investigation: who needs this information and how to use the information. However, the reality is, according to the Chinese AEC industry, the modeler needs to complete the modeling in very tight time so that they have no time to do the investigation.

This may be the current situation of China's BIM application market.

\subsection{Objectives of the Research are to}

$>$ Provide the employer information requirements from the literature review, working experience, and case studies.

$>$ Explore the original scheme of 4D simulation.

$>$ According to the investigation, understand the AEC industry's understanding of BIM application.

\section{Literature Review}

\subsection{Introduction}

Here will introduce some specifications of UK( and China. However, at the same time, the contemporary situation of BIM application cannot be ignored. The investigation will reveal the main applications and requirements of BIM in China.

\subsection{Specific Guidance by BSI}

\subsubsection{PAS1192-2}

'Specification for information management for the capital/delivery phase of construction project using building information modeling' (PAS1192-2) provides specific guidance for the information management requirements associated with projects delivered using BIM. Moreover, it describes the BIM maturity levels and requirements of information delivery.

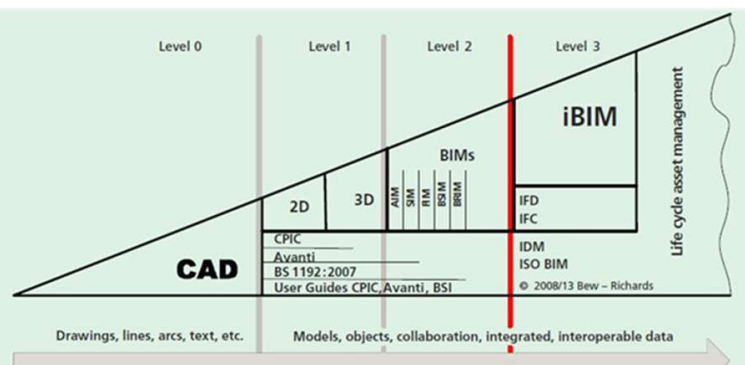

Figure 3 - BIM maturity levels

Figure 3 illustrates the main elements of the various stages of the BIM technology development process, as well as the expected of the BIM.

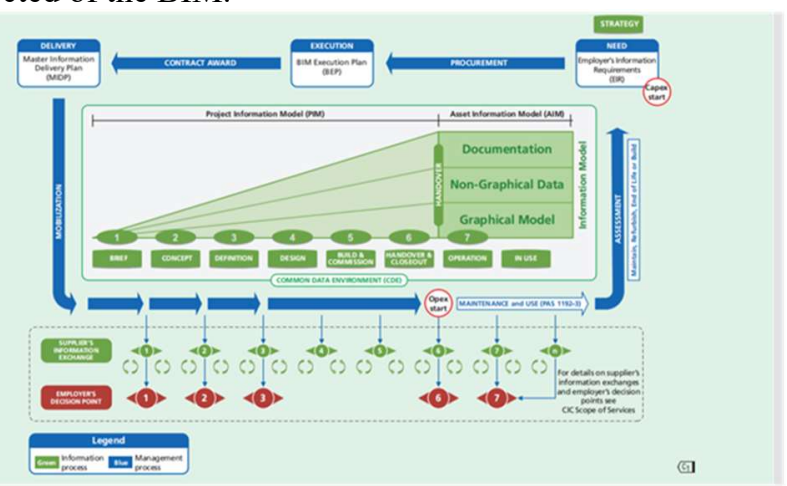

Figure 4 - The information delivery cycle

Figure 4 shows the information delivery and project management cycle. The BLUE cycle describes the generic process of identifying a project need, procuring and awarding a contract, mobilizing a supplier and generating production information and asset information relevant to the need. This cycle is followed for every aspect of a project shown in GREEN.

The contents of the employer's information requirements(EIR) shall be identified into the tender documents.

$>$ Levels of detail

$>$ Training requirements

$>$ Planning of work and data segregation

$>$ Co-ordination and clash detection

$>$ Collaboration process

$>$ A schedule of any security and integrity requirements for the project

$>$ A schedule of any specific information to be either excluded or included from information models

$>$ A schedule of any software formats, including version numbers that shall be used by the supply chain to deliver the project

$>$ Exchange of information

$>$ Client's strategic purposes

Figure 5 shows the extending common data environment (CDE). 


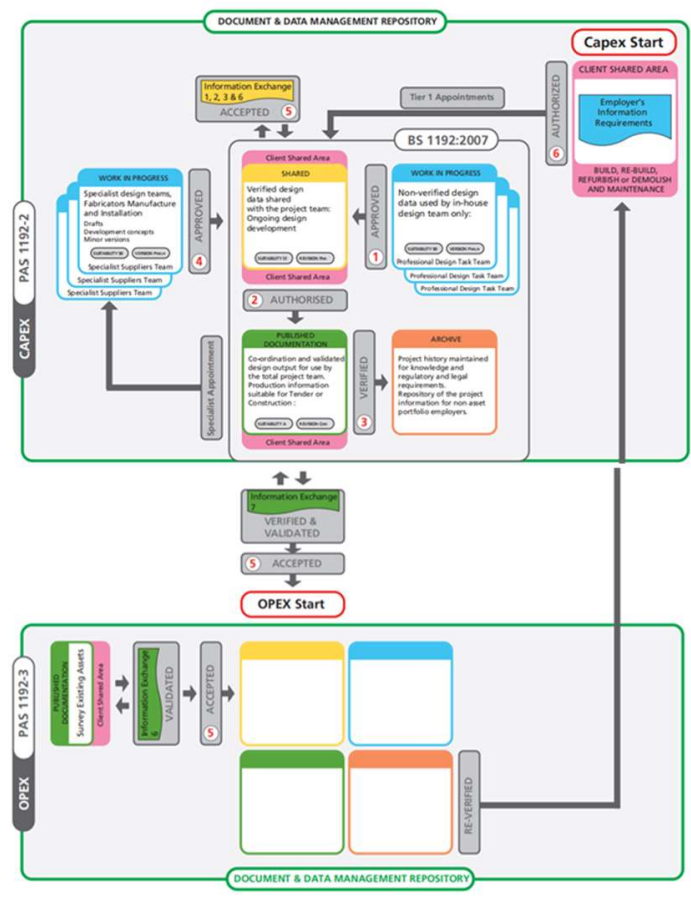

Figure 5 - Extending the common data environment 2.2.2PAS1192-3

'Specification for information management for the operational phase of assets using building information modeling' (PAS1192-3) is a companion document of PAS1192-2. The relationship between these two specifications can be seen from Figure6.

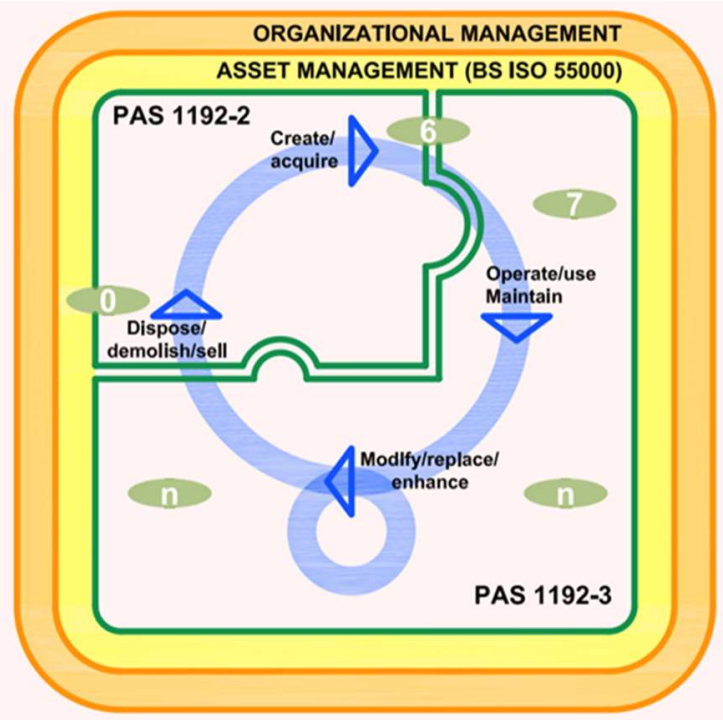

Figure 6 - Relationship between PAS1192-2 and PAS1192-3 The specification describes an asset information management process. The common data environment extracts from Figure 5 and is shown as Figure 7.

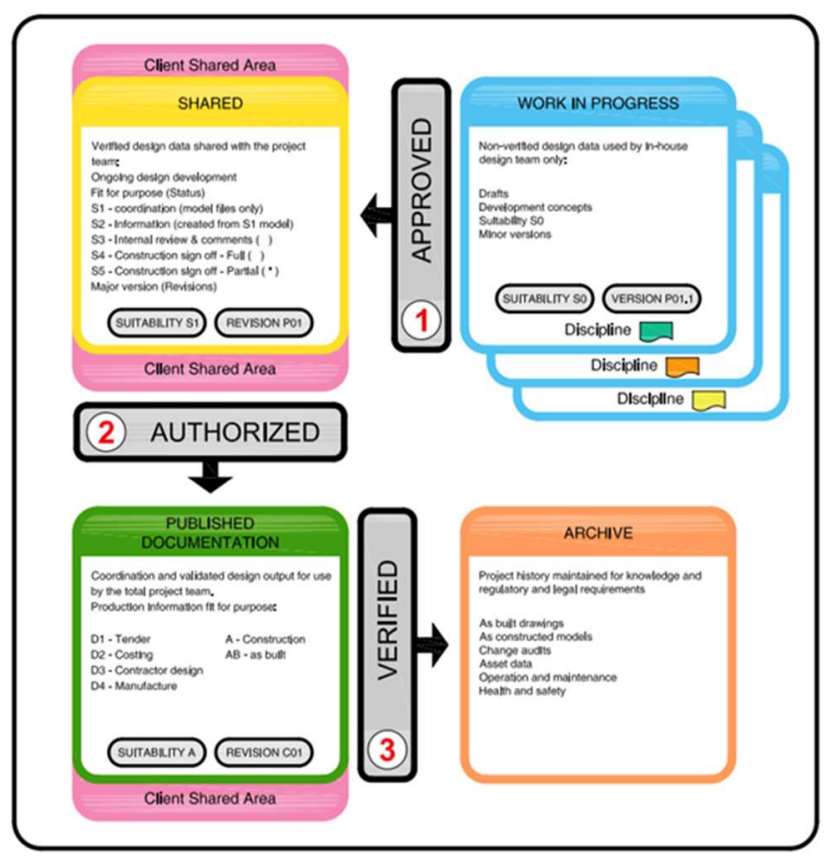

Figure 7 - The common data environment extracted from PAS1192-2

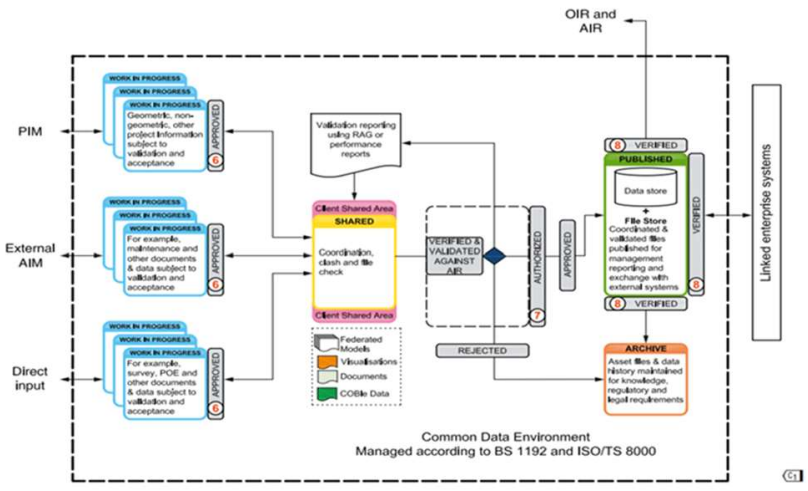

Figure 8 - Process map within the CDE

The processes of providing the CDE should be implemented by the employer as soon as an asset has been handed over. The map of the process is shown as Figure8.

\subsubsection{PAS1192-6}

'Specification for collaborative sharing and use of structured health and safety information using BIM' (PAS1192-6) provides guidance on how $\mathrm{H} \& \mathrm{~S}$ information is produced slows and can be used throughout the project and asset lifecycle. Figure 9 shows the progressive development of $\mathrm{H} \& \mathrm{~S}$ information.

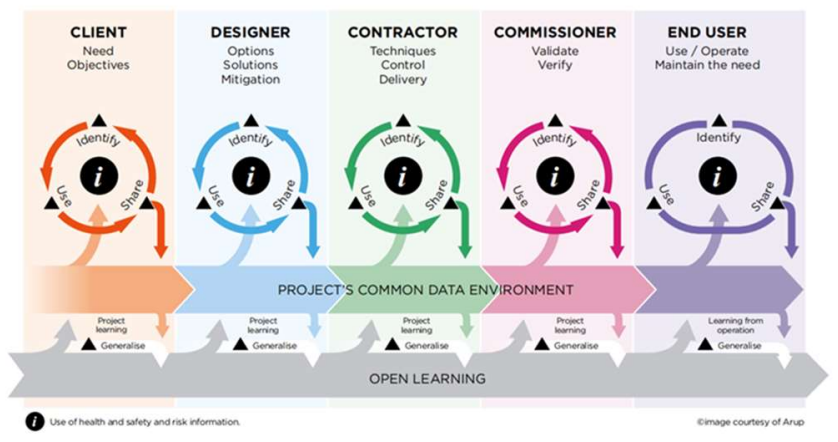

Figure 9 - Progressive development of H\&S information 


\subsection{Guidance issued by MOHURD (China)}

Influenced by the new technology innovation of the construction industry in developed countries, BIM technology has been rapidly developed in China's domestic construction field. First, Ministry of Housing and UrbanRural Development of the People's Republic of China (MOHURD) issued the 'Outline of Construction Information Development 2016-2020'. In this document, it is pointed out that the five major information technologies, including BIM technology, should be promoted. Subsequently, MOHURD issued another document, a standard of BIM application (GBT51212). GBT51212 identifies basic requirements of BIM, BIM model structure and extension, data interoperability, and BIM applications.

According to the investigation, the number of projects which have used BIM technology reached the amount of 423 between 2015 and 2016 in Shanghai. Also, the Department of Urban-rural Construction Committee of Shanghai had published a series specification for BIM applications by the end of 2016, including but not limited the following documents:-

$>$ Application standard of building information modeling

$>$ Technical standard for building information modeling of urban rail transit

$>$ Delivery standard for building information modeling of urban rail transit

$>$ Application standard for building information modeling of water supply and drainage

$>$ Application standard for building information modeling of road and bridge

With the experience's accumulation of the application of BIM, the government of Shanghai continued to launch the guidance and training for the professional personnel. Figure 10 shows the number of projects using BIM technology in 2016. Figure 11 reveals the type of project using BIM technology.

\subsection{Current Situation}

The number of enterprises which applies the BIM technology is increasing in recent years, while the application of BIM technology in China has been more popular.

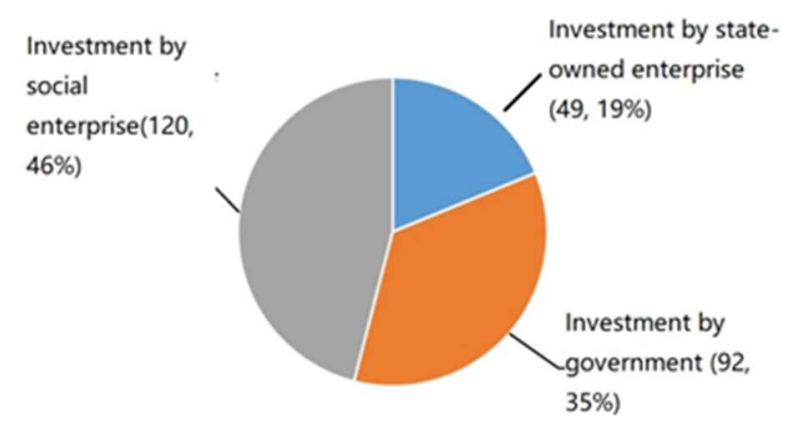

Figure 10 - The investment type of project in 2016

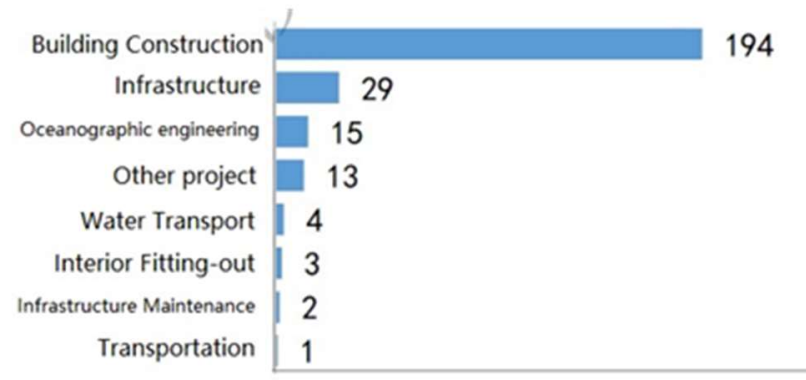

Figure 11 - The type of project in 2016

Figure 12 reveals the application contents of BIM in Shanghai. It is evident that visualization and aided design are still the main application points at the contemporary. Conflict detection, model building, and virtual roaming are the dominant applications. Figure 13 shows the application of software including the domestic and international productions in Shanghai.

\begin{tabular}{|l|c|}
\hline Conflict detection and pipeline integration & $65 \%$ \\
\hline Setting up the modelling & $65 \%$ \\
\hline Plan/Elevation/Section inspection & $61 \%$ \\
\hline Virtual Roaming & $56 \%$ \\
\hline Shop drawing design & $49 \%$ \\
\hline Space optimization & $46 \%$ \\
\hline Quantities calculation & $44 \%$ \\
\hline Simulation of construction scheme & $43 \%$ \\
\hline Comparison of schedule & $40 \%$ \\
\hline Comparison of design scheme & $37 \%$ \\
\hline Quality and safety management & $32 \%$ \\
\hline Analysis of site & $32 \%$ \\
\hline Facilities management & $27 \%$ \\
\hline Completion modelling & $19 \%$ \\
\hline Operation system & $6 \%$ \\
\hline Asset management & $5 \%$ \\
\hline
\end{tabular}

Figure 12 - Application contents

\begin{tabular}{||l|c|l|l|}
\hline Revit & $83.9 \%$ & Project Wise & $23.2 \%$ \\
\hline Navisworks & $67.9 \%$ & Civil 3D & $23.2 \%$ \\
\hline Tekla & $46.4 \%$ & PKPM & $21.4 \%$ \\
\hline 3DS Max & $44.6 \%$ & Ecotect & $17.9 \%$ \\
\hline Autodesk 360 & $39.3 \%$ & Catia & $17.9 \%$ \\
\hline Sketchup & $37.5 \%$ & Bently & $12.5 \%$ \\
\hline Luban (鲁班) & $35.7 \%$ & Archibus & $8.9 \%$ \\
\hline Rhino & $30.4 \%$ & iTwo & $7.4 \%$ \\
\hline Glodon (广联达) & $28.6 \%$ & Vico & $5.4 \%$ \\
\hline ArchiCAD & $25 \%$ & Micro Station & $5.4 \%$ \\
\hline
\end{tabular}

Figure 13 - Software

\subsection{Investigation of Contemporary Practice}

Questionnaire is excerpted from the company internal journal of the author; which content mainly includes the following aspects.

$>$ The role of respondents and the length of employment

Figure $14 \& 15$ illustrate that the interviewee has rich experience in AEC industry.

$>$ Current understanding of BIM

Most of interviewee consider that the application of BIM includes the design optimizing, 3D roaming, 
facilities management, which is the problem discussed in section 1.3.4.

$>$ Current disadvantage of project management in cost control and schedule management

$>$ Advantage of BIM

$>$ Which aspects of BIM application that interviewees want to know

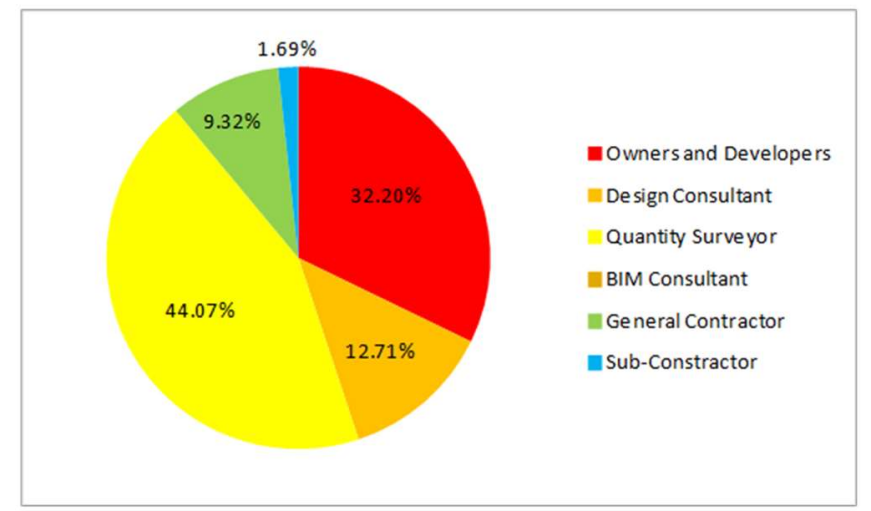

Figure 14 - Respondents distribution

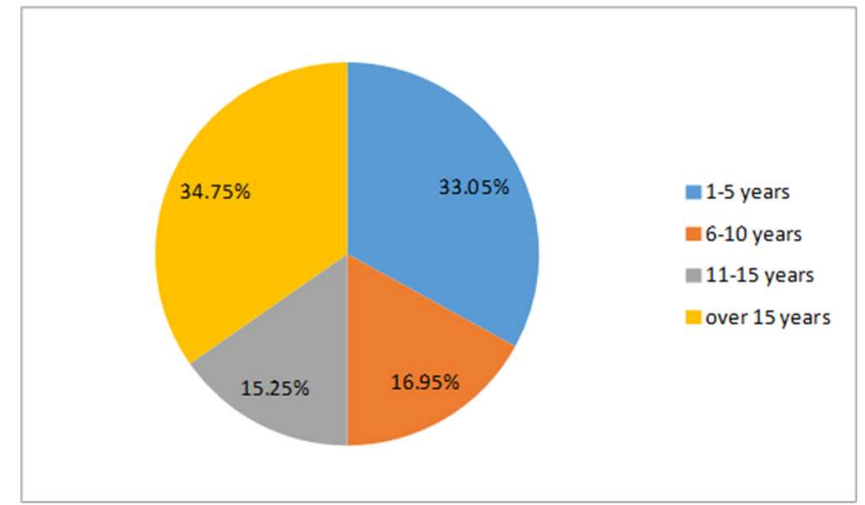

Figure 15 - Length of employment

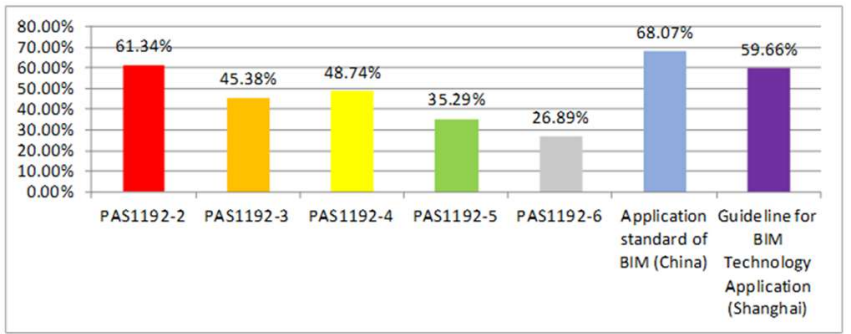

Figure 16 - The specifications (the respondents want to know)

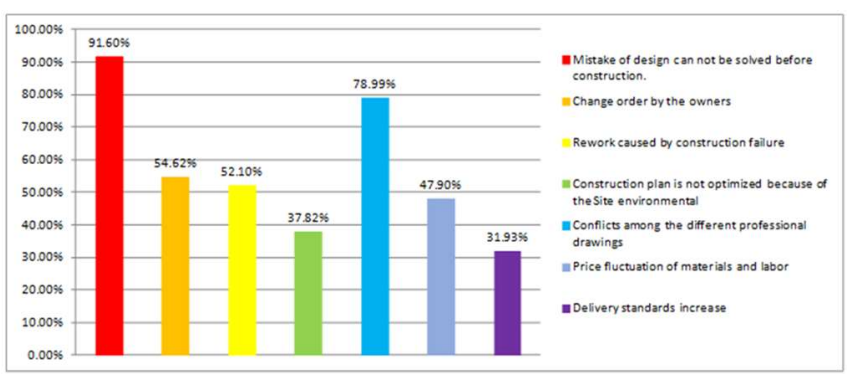

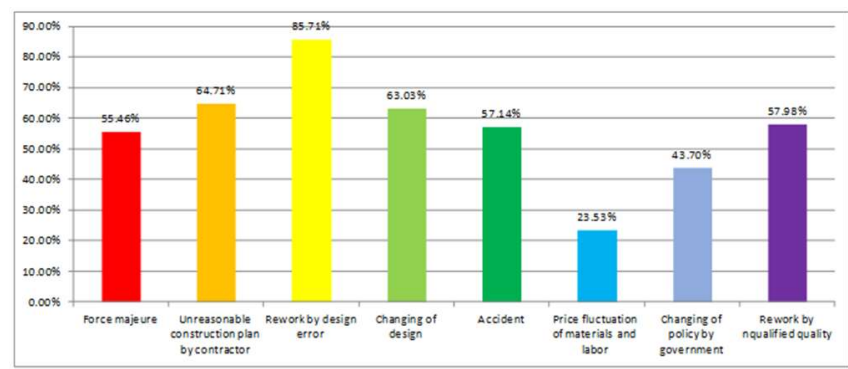

Figure 17 - Influence factor for cost and schedule

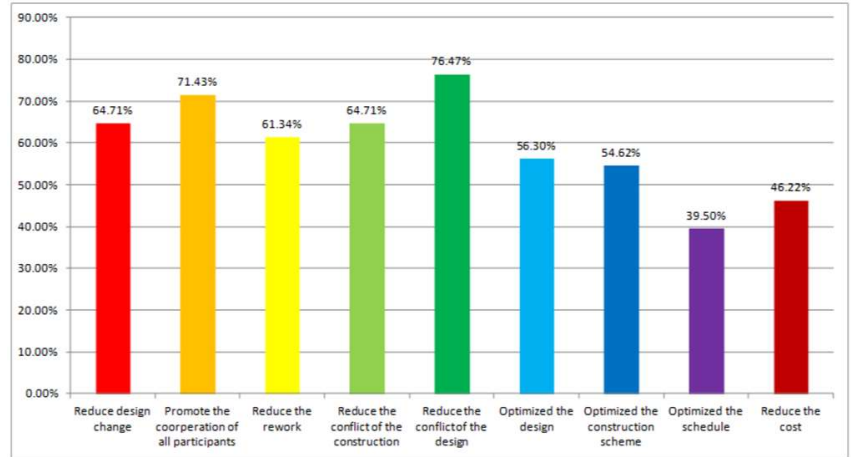

Figure 18 - the advantages and distribution ratios of BIM applications

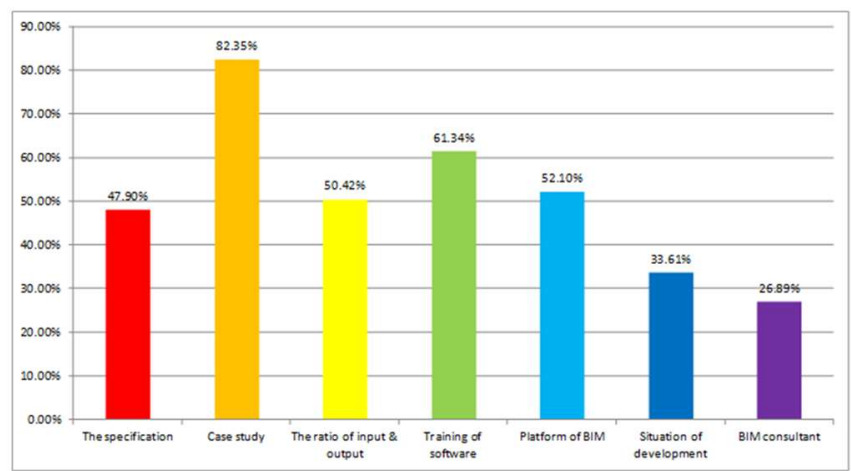

Figure 19 - Expectation

\section{Case study}

PDCA is widely used in the whole world for the project management. We do case studies and focused on cost saving and schedule optimizing. Then we go through the case of platform for enhancing the quality of project management. In this research, there will be 3 case studies.

$>$ Case 1-4D simulation for a typical residential project in China.

$>$ Case 2 - Application of BIM by the platform

> Case 3-Application of BIM in airport construction

The case studies will reveal the mainly BIM applications in China of different type of projects.

\section{$3.14 D$ Simulation}

The project is situated at Yuhang District, Hangzhou, Zhejiang Province and a mix-used project, which is included commercial and residential. The research is focused on Block 2 of the residential.

Block 2 has 180 units, with 31 floors. In this case study, it is assumed as 19 floors. 


\begin{tabular}{|c|c|c|}
\hline Item & Start & Complete \\
\hline Structural work & $2015 / 5 / 16$ & $2016 / 1 / 31$ \\
\hline $2 \#$ & & \\
\hline $1-5 \mathrm{~F}$ & $2015 / 5 / 16$ & $2015 / 6 / 30$ \\
\hline $6-10 \mathrm{~F}$ & $2015 / 7 / 1$ & $2015 / 8 / 10$ \\
\hline $11-15 \mathrm{~F}$ & $2015 / 8 / 11$ & $2015 / 9 / 15$ \\
\hline $16-19 \mathrm{~F}$ & $2015 / 9 / 16$ & $2015 / 10 / 20$ \\
\hline
\end{tabular}

Figure 20 - The initial plan

The project schedule had been influenced by some unforeseeable reasons. The start of the project was delayed by about 40 days.

3.1.1 The modeling

According to the drawings, the modeling had been built as Figure 21. The modeling includes the critical information of the structure.

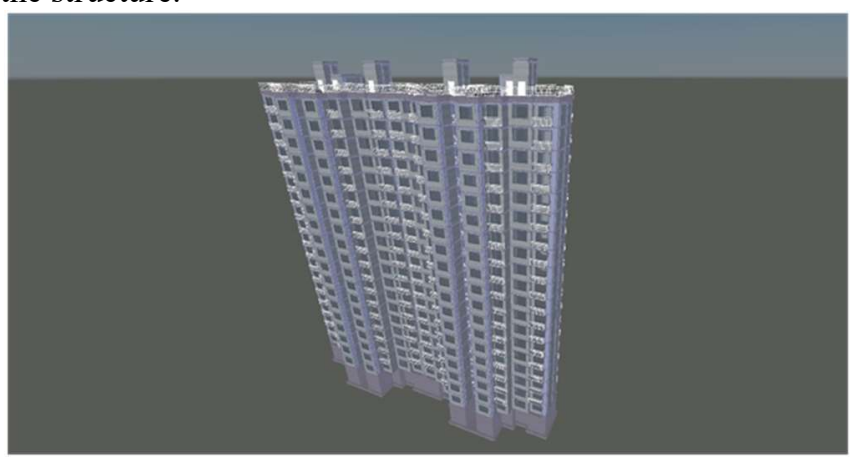

Figure 21 - The modeling

3.1.2 The schedule

The delay of commencement will influence about two months for the vital route of the project. So we simulated for the structure and searched the possible schedule for catching up the plan.

The construction time of each floor is set by 7 to 8 days in the plan. In order to match the plan, we planned to reduce the time to 5 days. The schedule would catch the plan on 19 Floor. Also, the schedule of construction had been adjusted as Figure 22.

\begin{tabular}{|c|c|c|}
\hline Item & Start & Complete \\
\hline 1F & $2015 / 6 / 27$ & $2015 / 7 / 7$ \\
\hline 2F & $2015 / 7 / 8$ & $2015 / 7 / 13$ \\
\hline $3 F$ & $2015 / 7 / 14$ & $2015 / 7 / 19$ \\
\hline $4 F$ & $2015 / 7 / 20$ & $2015 / 7 / 25$ \\
\hline $5 F$ & $2015 / 7 / 26$ & $2015 / 7 / 31$ \\
\hline $6 F$ & $2015 / 8 / 1$ & $2015 / 8 / 6$ \\
\hline $7 F$ & $2015 / 8 / 7$ & $2015 / 8 / 12$ \\
\hline $8 F$ & $2015 / 8 / 13$ & $2015 / 8 / 18$ \\
\hline $9 F$ & $2015 / 8 / 19$ & $2015 / 8 / 24$ \\
\hline $10 F$ & $2015 / 8 / 25$ & $2015 / 8 / 30$ \\
\hline $11 F$ & $2015 / 8 / 31$ & $2015 / 9 / 5$ \\
\hline $12 F$ & $2015 / 9 / 6$ & $2015 / 9 / 11$ \\
\hline $13 F$ & $2015 / 9 / 12$ & $2015 / 9 / 17$ \\
\hline $14 F$ & $2015 / 9 / 18$ & $2015 / 9 / 23$ \\
\hline $15 F$ & $2015 / 9 / 24$ & $2015 / 9 / 27$ \\
\hline $16 F$ & $2015 / 9 / 28$ & $2015 / 10 / 3$ \\
\hline $17 F$ & $2015 / 10 / 4$ & $2015 / 10 / 9$ \\
\hline $18 F$ & $2015 / 10 / 10$ & $2015 / 10 / 15$ \\
\hline $19 F$ & $2015 / 10 / 16$ & $2015 / 10 / 20$ \\
\hline
\end{tabular}

Figure 22 - revised schedule

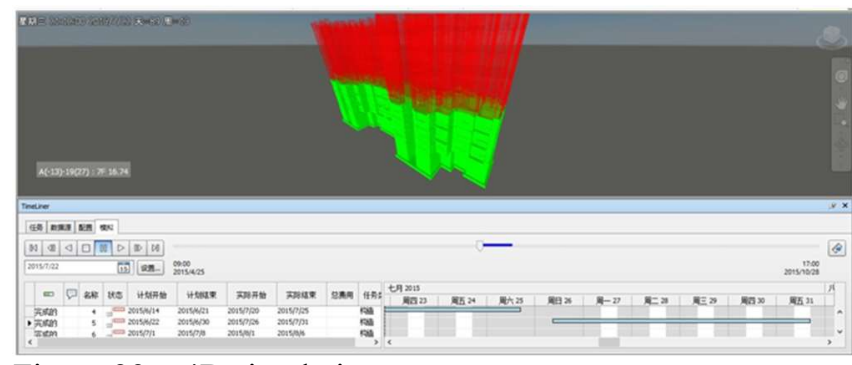

Figure $23-4 \mathrm{D}$ simulation

The red part represents the building that should be completed according to the plan. The green one represents the building that is built by the new schedule.

3.1.3 Solution

The construction of each floor should be adjusted based on the new schedule. In order to achieve the goal, the personnel arrangement and preliminary adjustments had been made. The estimates of these have been made according to the situation. The cost had increased. However, the original plan had been met, and the loss of deferred cost has been avoided (e.g., liability for breach of contract for the delay, increased management cost).

\subsection{Platform for BIM application}

BIM (Shanghai) Building Data Technology is a professional technical service supplier, which is focused on BIM application for the construction project. One of its product, named Building data integrate platform' (BDIP), is BIM application based on modeling from project design to completion stage of project construction.

This case is a residential project situated in Beijing. The BIM applications are mainly used in the following aspects.

\subsubsection{Design collaboration and collision analysis}

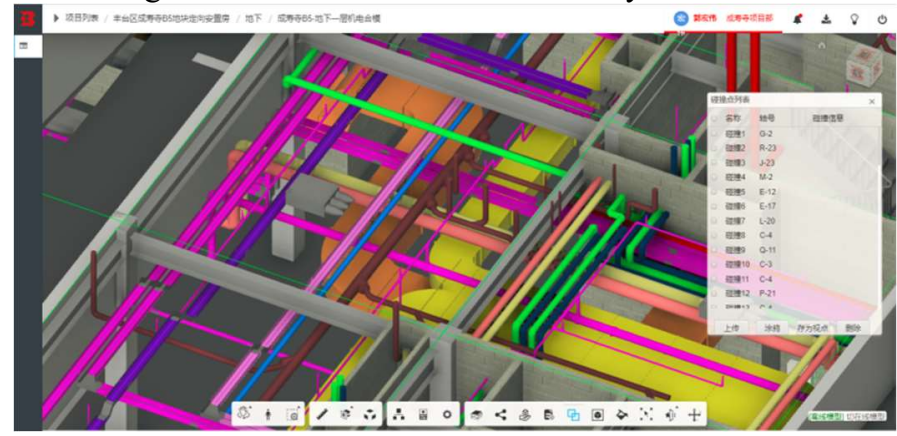

Figure 24 - collision analysis

Figure 24 reveals the collision analysis. All of the participants can get the same information according to their unique ID by the BDIP.

\subsubsection{Payment management}

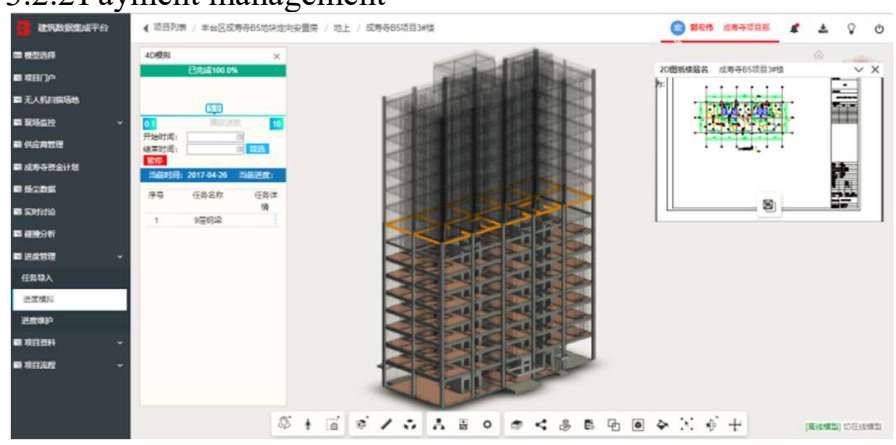




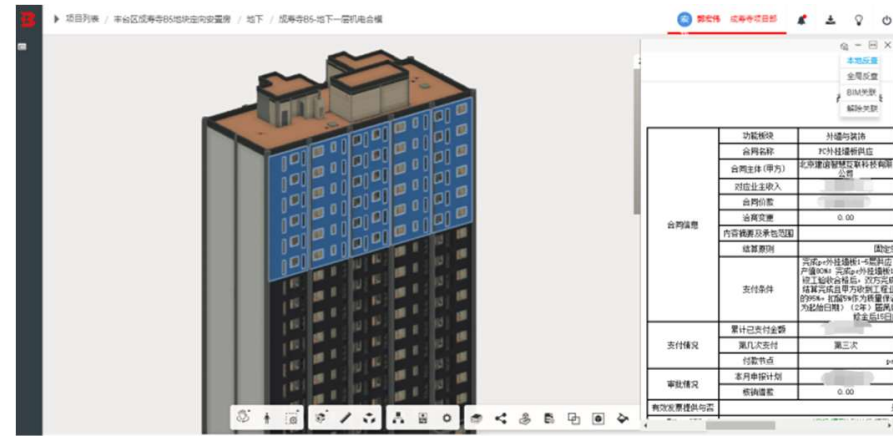

Figure $25 \& 26$ - payment

Figure 25 shows the actual progress of the project so that the client can confirm the payment, which is based on the contract conditions and the project progress (Figure 26).

3.2.3 Document management

BDIP can make a common data environment (CDE) for the project (which was discussed in 1.3.2). The 2D drawings can be related to the $3 \mathrm{D}$ modeling. Also, all of the revised editions can be stored in this platform by the potential rules. All of the participants can find whatever they want to know about the design documents during the different stages of the project.

3.2.4 Supplier management

The platform also combines the supplier information. The products used in the project can be easily found in the model. Moreover, the details of the equipment, such as the installation date, maintain contact, and manufacturer address and so on would be reported in the modeling. Figure 27 shows an example of the supplier's address by the map.

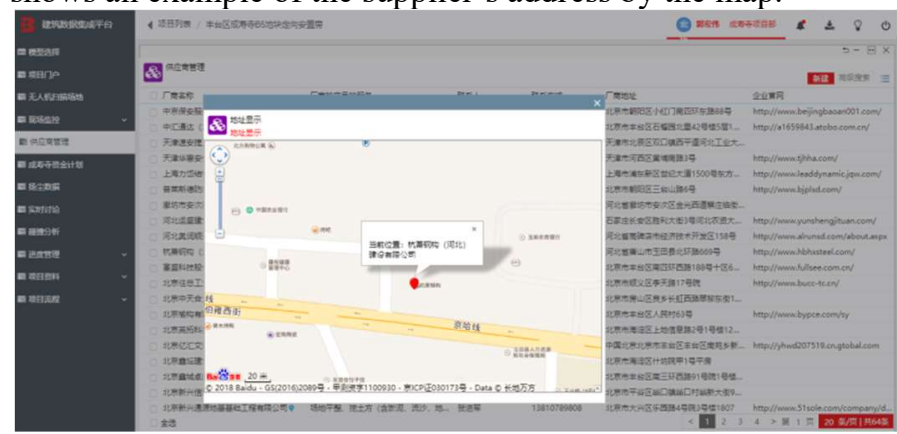

Figure 27 - the information of supplier

The company has developed several BIM application platforms, such as BIM-FM collaboration platform. Moreover, several infrastructure projects had been completed, such as Metro in Wuhan and so on.

\subsection{Application of BIM in airport construction}

Beijing Daxing International Airport is a super-large integrated international air transportation hub between Daxing District of Beijing and Guangyang District of Langfang City, Hebei Province. According to the scale of 100 million passenger throughput and 800,000 aircraft takeoffs and landings (2040), seven runways and about 1.4 million square meters of terminal buildings will be built. This case is based on the maintenance of locomotive for the China Eastern in this new airport. It combines the original OA system with BIM collaborative management system.

\subsubsection{Design collaboration}

In the initial design stage, the modeling has been built for the visualization. At the same time, the BIM audit process has been worked out for all of the participants as the Figure 28.

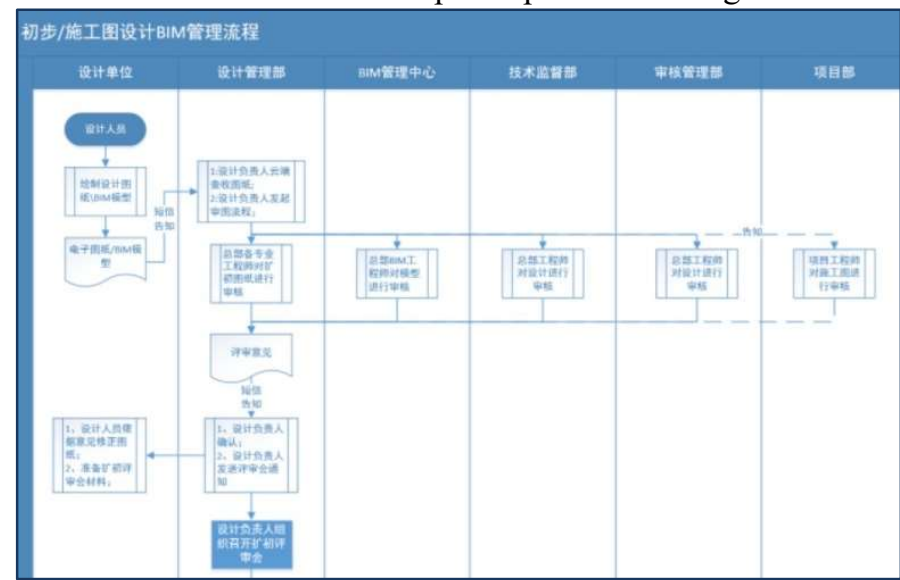

Figure 28 - the Process

It also applies the modeling for outputting the 2D drawings directly in M\&E systems. Figure 29 shows the modeling reserves reasonable installation and operation space for equipment and pipeline.

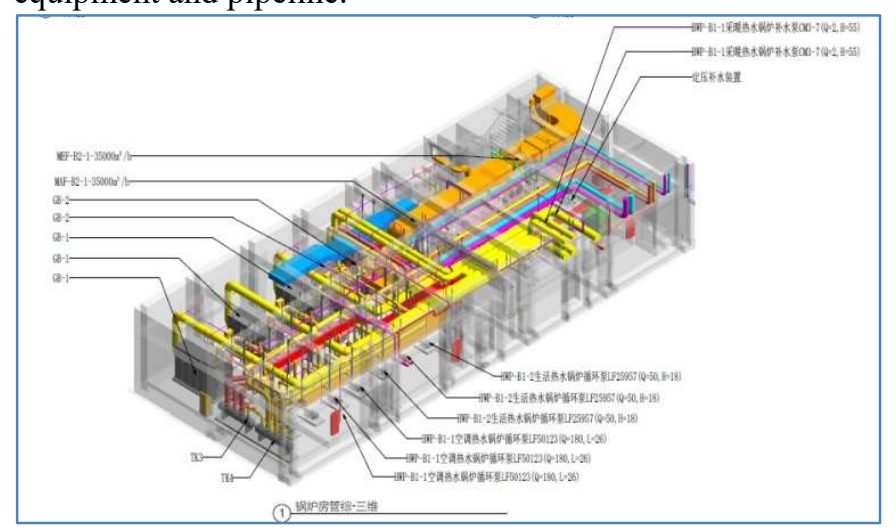

Figure 29 - The modeling

3.3.2 Setting out on site

By comparing the aerial view photos with the modeling, the errors between the actual scene and the model are avoided, and the construction accuracy is increased. When we enter the site, BIM lofting robot is used to collect data from the site control points and locate them.

3.3.3 The platform for project management

China Eastern Airlines invested in the research and development of information collaboration platform with Glodon in-depth cooperation. Based on the standardized products of Glodon BIM5D, a BIM collaborative management platform is designed according to the characteristics of the construction projects of China Eastern Airlines. The platform further implements the project management policy of China Eastern Airlines, which takes headquarters as the main force and carries out the trunk of the project, promotes and improves the quality and safety of project management and enhances the presentation and application of progress control data. 


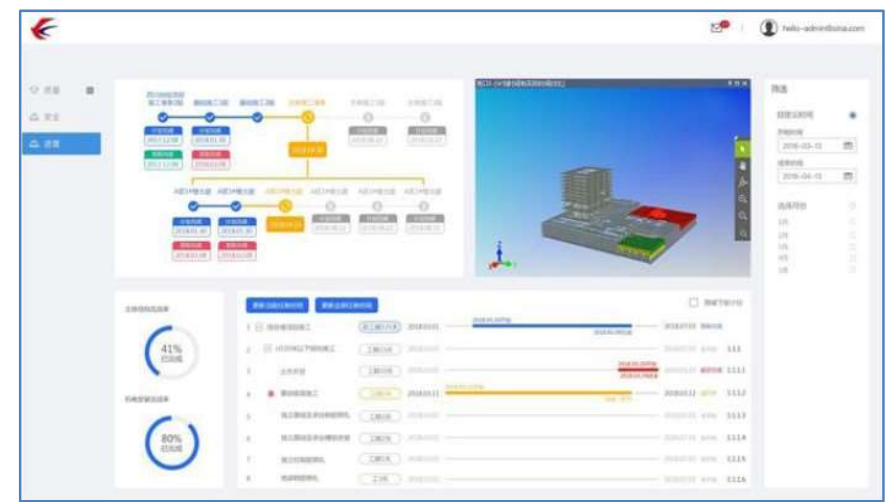

Figure 30 - The platform

\section{Analysis}

According to the literature review and the case studies, we have a preliminary understanding of the BIM standard and the application in the Chinese market.

In the whole world, the application of BIM has attracted the attention of all countries, and in recent years has been rapid development. Among them, the BSI (British Standards Institution) standard is the most comprehensive and is also actively promoting the application of BIM Level 2 and Level 3. China's standards are in the process of gradual improvement. However, due to a large number of construction projects in China and the vigorous implementation of BIM by governments at all levels, there are more actual cases of BIM applications.

The main application is shown as the following aspects:-

$>$ The proposed project in the three-dimensional model roaming, feel the scale of the design space in advance while optimizing the use of space.

$>$ Design conflict inspection helps design correct errors and omissions and reduces cost and time loss during construction.

$>$ To help the project management team to understand the whole construction process more intuitively, and to solve the severe problems in the process of project construction.

$>$ During the operation and maintenance stage, it is more convenient to browse the device information quickly through the modeling.

\subsection{Advantage}

We can find out the advantage of BIM application to enhance the quality of project management.

$>$ Reducing the cost

$>$ More efficient coordination and communication

$>$ Managing the project under the unified standard

\subsection{Disadvantage}

It also has some disadvantage during the research of case studies.

4.2.1 The time for the modeling

There is a shortage of people who can model professionally. At the same time, considering the requirement of model quality, modeling time has become a significant problem that restricts the application of BIM. For example, People with one year's modeling experience are about 500 square meters per day in the process of building structural models. If there are more complex structural forms, the modeling efficiency is lower

Therefore, considering the establishment of the family library system for standard building products will speed up the modeling speed to a certain extent. However, architectural design is usually unique, so this method is only applicable to enterprises with a single form of building products, such as those focusing on the development of residential projects.

4.2.2Quantity automatic measurement by mode

During the investigation, the researcher also discussed with the interviewee about the quantity measurement by model. The results of automatic measurement will be affected by the accuracy of the model. It will issue the wrong data because of the incorrect modeling.

Besides, even though the model is accurate, the default deduction rules for overlapping parts of different components are different due to the different habits of the modelers, which may not necessarily match the contract calculation rules.So it is essential to establish the standards of modeling, which can match the contract conditions as discussed in Chapter 3. The calculation rules and the explanation of unit price should be considered. Moreover, at the same time, the standard should be accepted by all of the participants, such as quantity surveyor and contractors and so on.

4.2.3 Model revised during the construction period

In the construction period, the design is probably to be modified. So the modeling should be revised at the same time. However, the reality phenomena proved this action is difficult to be followed by the BIM consultant.

The main reason is that BIM consultants cannot get the relevant design information as soon as possible. In general, the design consultant notifies the project manager of the design revision, and the project manager pays attention to the impact of the decision on the construction period and cost. So that he would communicate with the contractor and the quantity surveyor, usually, the information for BIM consultant will be ignored.

The regular of the information transmission and the communication rules should be the basic requirements for the project management team. A perfect system can avoid the loss of the information.

\subsubsection{Training}

The establishment of the model, the use of the model, the common understanding of BIM application, especially the specification, the confirmation of basic requirements such as CDE, EIR, all participants in the project need to be trained. This kind of training needs professional guidance, which will bring the extra cost to the owners compared with the traditional project management methods. At the same time, in addition to the cost for owners, the participants also need to use additional human resources. For the current requirements of the AEC industry in China, the situation is disliked by many owners. However, we can notice that the government has begun to promote the BIM application in infrastructure projects. The general training has held in lots of developed country, as well as in China.

\section{Conclusion}

In this research, we found that the application of BIM is more and more extensive in China. However, from the owner's point of view, there are not many cases of BIM application in project management. Therefore, a broader introduction of the latest specifications (such as BSI standard) and the 
application of BIM in a unified data environment and evaluation to develop standard workflow and requirements will help project management to be more efficient.

\section{Acknowledgments}

I wish to acknowledge the contribution that the following people have made to the completion of this paper.

I want to thank Mr. Yang Lin, Senior researcher of D-CiTi Lab of UNNC for his documents about the policies of BIM application in China.

I want to thank Mr. Lin Min, Mr. Xiong Wei, the consultant of BIM for their technical supporting in case studies.

\section{References}

\section{Journal articles}

Nguyen, L., Phan, D., and Tang, L. (2013) Simulating Construction Duration for Multistory Buildings with Controlling Activities, ASCE Journal of Construction Engineering and Management, 139(8), pp. 951-959.

Tang, L.C.M., Zhao, Yuyang, Austin, S.A., Darlington, M.J. and Culley, S.J. (2010b) Codification vs personalisation: A study of the information evaluation practice between aerospace and construction industries, International Journal of Information Management, 30(4), pp. 315-325.

Zhao, Yuyang, Tang, L.C.M., Darlington, M.J., Austin, S.A. and Culley, S.J. (2008) High value information in engineering organisations, International Journal of Information Management, 28(4), pp. 246-258.

Ruoyu Jin, Craig Hancock, Llewellyn Tang, Chao Chen, Dariusz Wanatowski, Lin Yang (2017) An Empirical Study of BIM-Implementation-Based Perceptions among Chinese Practitioners, ASCE Journal of Management in Engineering, 33(5)

\section{Books}

BIM for Building Owners and Developers, Hoboken, N.J. :

Wiley, Hoboken, N.J. : Wiley

Project Management (tenth edition), Dennis Lock. Gower Publishing Limited, Burlington, Vt.: Gower

PAS 1192-2, Specification for information management for the capital/delivery phase of construction project using building information modeling, BSI

PAS 1192-3, Specification for information management for the operational phase of assets using building information modeling, BSI

PAS 1192-6, Specification for collaborative sharing and use of structured health and safety information using BIM, BSI

\section{Conference paper}

CHEN, Chao and Tang, Llewellyn (2018) An empirical study of impact factors on production control of construction process within BIM, Engineering, Construction and Architectural Management (Under review)

Shen, X., Kecheng L., Llewellyn, C.M.T. , and Weizi, L. (2016) A Framework for Integrating Syntax, Semantics and Pragmatics for Computer-aided Professional Practice: With Application of Costing in Construction Industry, Computers in Industry, 83, 28-45.

\section{Websites}

https:/www.itwo.com/cn/itwo-4-0-5d-bim企业级云平台/ Architecture Science and Technology (WeChat, 21st Sep, 2017)

http://www.17bim.com/ 